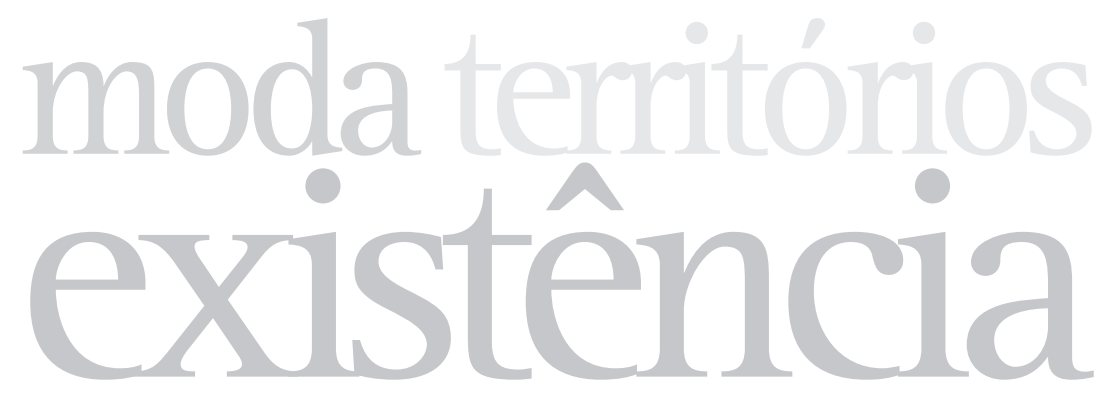

Em 2011, publicamos o livro Moda em ziguezague: interfaces e expansões, uma coletânea de artigos que reúne múltiplas vozes, provenientes de vários campos do saber. Sabíamos do desafio que representaria congregar essas vozes tão heterogêneas e dispares. No entanto, estávamos convictas de que esse gesto era necessário e produtivo. Nosso convite era para pensar a Moda de forma fronteiriça, logo, arriscada. Decerto um lugar assim sem lugar, alargaria sua compreensão e poderia conduzir reflexões por caminhos mais improváveis e, quem sabe, mais reveladores.

Acreditamos que o artigo que se segue ilustra o que acabamos de dizer. Nele, busca-se compreender aspectos da lógica de construção de blocos de sentido na obra do designer de moda inglês Alexander McQueen, sob o viés da filosofia, mas articulando também noções de estética, semiótica e design, ancorando-se sobretudo no conceito de imanência, explorado na obra do filósofo francês Gilles Deleuze (1925-1995).

Entre outros, um dos objetivos é estabelecer vizinhança entre os procedimentos do designer com os do pintor anglo-irlandês Francis Bacon (1909-1992) - que comparece no papel de intercessor - a partir do pressuposto do desejo. Valendo-se do instrumental teórico deleuziano, o desejo é abordado não como falta, como de costume no viés psicanalítico, mas sim como potência, derivada da corrente filosófica conhecida como Vitalismo, que encontra no filósofo holandês Espinoza (1632-1677) sua expressão. Para muito além de uma abordagem sobre os produtos e resultados de uma coleção do designer, trata-se de apontar para um universo das afecções dos corpos, sejam eles físicos ou imateriais.

No intuito de refletir de que modo os significantes operam no processo de criação de McQueen, quatro seções temáticas são abordadas: a imanência e o devir; o trágico e a deriva; o hibrido e o louco; a sustentabilidade e a crise. Cabe ressaltar o empenho dos autores em cada seção, no sentido de construir campos de significação que possam trazer à tona algumas das chaves de compreensão para determinados caminhos delineados na coleção Plato's Atlantis (primavera-verão 2010) .

Os leitores poderão testemunhar que não se trata de uma tarefa simples essa de alinhar no plano da criação dois autores do porte de McQueen e de Bacon, ambos donos de vitalidade e complexidade ímpares e indiscutíveis. Nesse contexto, ensaiam-se aqui formulações em nada conclusivas, porém experimentais. Em outras palavras, este texto não se propõe a postular nem concluir nada, mas provocar reflexões oriundas de diálogos, da produção de conexões possíveis, da indicação de especulações a partir de conteúdos imanentes. Dessa maneira, a proposta de aproximação entre o campo da moda e o da filosofia se mostra como uma investigação inusitada, instigante e inspiradora, aberta para ser trilhada por outros olhares.

Por fim, vale mencionar também a ênfase que esta abordagem rizomática aponta para as ligações do trabalho de McQueen com a arte, a mitologia e a literatura. Esta postura dos autores também é bastante bem-vinda no Grupo de Trabalho Moda e Territórios de Existência: Processos de Criação e Subjetivação, cujo desejo é abrigar pesquisas que abordem o campo da moda, suas variáveis e suas materialidades como dispositivos atrelados à subjetividade, capazes de maquinar territórios estéticos e existenciais. Nesse contexto, compreendemos que os modos de funcionamento da moda desdobram-se em constantes diálogos com vários outros campos do saber. A proposta de enfatizar processos de criação hibridos que redimensionem a própria conceituação da moda, expandindo linhas de compreensão e gerando novos conhecimentos, é estimulada pelo modo singular como este trio de autores explora as criações de Alexander McQueen e a estética em Plato's Atlantis. 
artigo $]$

[ FÁBIO PARODE | IONE BENTZ | MAXIMILIANO ZAPATA ]

Fábio Parode é doutor em Estética pela Paris 1 - Panthéon Sorbonne.

E-mail: fparode@gmail.com

Ione Bentz é doutora em Linguística e Semiótica pela Universidade de São Paulo.

E-mail: ioneb@unisinos.br

Maximiliano Zapata realiza Iniciação Científica em Filosofia na Pontifícia Universidade Católica do Rio Grande do Sul.

E-mail: maximiliano.zapata@acad.pucrs.br

\title{
Imanência e devir-animal na obra de Alexander McQueen
}

\author{
Immanence and animal-becoming in the \\ work of Alexander McQueen
}

[resumo] Este ensaio busca compreender aspectos da lógica de construção do sentido na obra do designer de moda inglês Alexander McQueen. Para enfrentar tal problema, aproximamos o campo da moda com o da filosofia e articulamos noções de estética, imanência, semiótica e design. Considerando que McQueen questionou o processo de desenvolvimento sustentável do planeta, abordaremos de forma especulativa conceitos e valores simbólicos presentes em sua obra para enfocar a temática da deriva cultural e da mutação da espécie humana. No escopo deste ensaio, organizado em quatro seções temáticas - a imanência e o devir; o trágico e a deriva; o híbrido e o louco; a sustentabilidade e a crise - questionaremos sobre a matéria semiótica de McQueen quanto à sustentabilidade, buscando conteúdos imanentes ao discurso do designer.

\section{palavras-chave}

moda; Alexander McQueen; cultura; devir; sustentabilidade.

[abstract] This essay seeks to understand aspects of construction of meaning in Englishman fashion designer Alexander McQueen's work. To address this problem, we have established a link between the fields of fashion and philosophy, as well as we articulated notions of aesthetic, immanence, semiotics and design. Considering that McQueen questioned the sustainable development process of the planet, we will speculatively address concepts and symbolic values in his works in order to focus the issue of cultural drift and mutation of the human species. In the scope of this essay, organized into four thematic sections - the immanence and the becoming; the tragic and the drift; the hybrid and the mad; sustainability and crisis - we will question about McQueen's semiotic theme in relation to sustainability, seeking immanent content to the designer's speech.

[keywords] fashion; McQueen; culture; the becoming; sustainability. 
0 presente ensaio propõe uma reflexão sobre a produção de sentido na moda, mais particularmente na moda proposta por Alexander McQueen (1969-2010). Para tal, de forma transdisciplinar, busca-se referências no campo da Filosofia, da Moda e do Design. Questiona-se a moda enquanto artifício de produção de conceitos, enquanto dispositivo e meio de se gerar novas experiências sensiveis. Interessa-nos aqui investigar a moda que segue a tradição filosófica de colocar questões, ou seja, a moda que faz filosofia, instigando a reflexão e deslocando a percepção comum. 0 objeto de moda em questão encontra-se nos limites da arte, inaugurando possibilidades inusitadas de sentidos. Assim, para dar conta do conjunto de questionamentos que pretendemos engendrar, partimos de um olhar semiótico sobre algumas peças do estilista inglês Alexander McQueen.

Gilles Deleuze, no seu livro Logique de la sensation (1981), faz uma investigação sobre o processo imanente na construção da imagem na obra de Francis Bacon, levantando questões sobre os princípios estéticos que regulam o processo de formação das imagens desse artista e sua possivel relação com os fluxos do desejo. Chega a conclusão de que Francis Bacon rompe com a narrativa inaugurando um espaço de isolamento da figura, o que, por analogia, nos remeteria a questionamentos sobre a condição humana, sua finitude e aos mecanismos que tolhem sua liberdade, que controlam sua libido.

Partimos do pressuposto que há entre McQueen e Bacon similaridades quanto à produção estética de suas obras, ou seja, quanto ao modo de operação do desejo no processo imanente que leva à construção de um imaginário que sustenta um repertório em termos de linguagem e expressão, como é o caso dos artefatos de moda e das obras de arte. Entretanto, se por um lado Bacon fez obras de arte, especialmente pinturas, cujo princípio imanente foi a violência, McQueen fez artefatos para moda, buscando um diálogo entre a linguagem dos estilos desse campo e a estética futurista inscrita em um mundo imaginário cuja ordem transcende os limites da fantasia, permitindo-nos associar suas imagens a estudos científicos e filosóficos sobre a mutação e a perspectiva híbrida da humanidade.

Sim, o desejo é a matéria-chave para compreendermos esse paradigma. 0 desejo na perspectiva deleuziana, ao contrário da compreensão psicanalítica, não é falta, mas sim potência. A própria noção de potência já derivada da corrente filosófica conhecida como Vitalismo (iniciada na Europa no século XVIII) tem em Espinoza um dos seus grandes pensadores, seja na ordem do elã vital, seja mais genericamente na da substância que corresponderia à energia dos corpos vivos em oposição ao mundo inerte. Os corpos vivos se reproduzem e, para tal, desenvolvem estratégias e táticas de sobrevivência, bem como mecanismos de conservação e expansão de seu gene. Assim, junto com a problemática da imanência dos corpos, sua potência e intensidade do desejo, encontra-se aquela que diz respeito à replicação do gene no tempo e no espaço, ou seja, a capacidade de reprodução e conservação das espécies. A autopoiese dos sistemas vivos é parte integrante desse processo. De todo modo, é fundamental percebermos o fato de que os corpos produzem um esforço para preservar-se na existência, caracterizando aquilo que Espinoza chama de conatus. Segundo ele, "[...] não é enquanto falta que o corpo procura aquilo que lhe é útil. $\dot{E}_{1}$ ao contrário, enquanto ele afirma positivamente sua própria natureza ou sua própria virtude, portanto, enquanto ele age segundo suas próprias leis, aquelas de sua natureza comunicacional" (ESPINOZA, 2002, p. 27, tradução nossa). ${ }^{1}$

Nessa esteira reflexiva, indo mais fundo na busca do substrato da obra de McQueen, ainda referimos Espinoza que percebe no horizonte das relações passionais estruturas que podem ser associadas à tristeza ou à alegria. É possivel construir um quadro de valores éticos com relação à preservação da vida, tendo como base essa dicotomia elementar entre o que produz tristeza ou alegria nos corpos. Essa lógica nos remete ao universo das afecções dos corpos, sejam eles físicos ou imateriais. Para o filósofo, a paixão triste tira a potência do corpo; já a paixão alegre coloca-o num movimento de realização de sua potência. Assim, percebe-se que todos os corpos estão em cadeia sistêmica, e do contato que uns têm com os outros, ou seja, 
do lugar onde é possível estar um pouco mais perto ou um pouco mais distante, afetase o outro em um continuum de espaço-tempo com maior ou menor intensidade.

No escopo deste ensaio, selecionamos um conjunto de artefatos, entre vestuário, sapatos e elementos de maquiagem, que compõem o cenário mítico e fantástico proposto por McQueen, durante o desfile Plato's Atlantis (primavera/verão 2010), em Paris.

Se, para Deleuze (1993, p. 10), "[...] a filosofia é a arte de formar, de inventar, de fabricar conceitos" consideramos que não seria tão diferente para McQueen do ponto de vista da moda. A moda de McQueen expande as sensações e nos leva às fronteiras entre o real e o surreal, descortinando não apenas imagens, mas estratégias discursivas com as quais nos revela seu universo pictórico por meio da moda. Sobre o que mesmo está tratando McQueen? Qual é a matéria de sua semiótica? 0 que a sustentabilidade tem a ver com o discurso desse estilista? As temáticas que se cruzam no discurso de McQueen e que serão abordadas neste ensaio são: a imanência e o devir; o trágico e a deriva; o híbrido e o louco; a sustentabilidade e a crise.

\section{A imanência e o devir-animal}

0 estilista Alexander McQueen instaurou com seu discurso de moda um significante inusitado no campo: o devir-animal do homem. 0 desfile Plato's Atlantis criou metáforas visuais para representar a intensidade animal no corpo do homem sob os signos da moda. No conjunto dessas metáforas aparece a condição trágica do humano, sua finitude como significante e o nascimento de um ser híbrido com a anatomia dos seres do mar.

Com base em Deleuze (1995), considera-se que as linhas e velocidades no discurso de McQueen apresentam-se por meio das formas rizomáticas e arborescentes, que, assim como ocorre em Bacon, remetem à violência do existir - afirmação de uma presença aprisionada em uma lógica de consumo permanente. Para o filósofo Deleuze (1995, p. 12), "[...] há linhas de articulação ou segmentaridade, estratos, territorialidades, mas também linhas de fuga, envolvimentos de desterritorialização. [...] Tudo isso, as linhas e as velocidades mensuráveis, constituem um agenciamento".

$\mathrm{Na}$ obra de McQueen, assim como na de Bacon, identificamos formas e signos que remetem a uma estética associada à violência. Formas de violência que gritam e não sussurram, permitindo a catarse pelo objeto esquizo, pela experiência estética que suscita a morte².

\section{0 trágico e a deriva}

A fuga do humano transparece na obra de ambos os artistas, multiplicidade de intensidades, expressões de uma existência em devir. Para Deleuze (1995, p. 46), "[...] linhas de fuga ou de desterritorialização, devir-lobo, devir-inumano, intensidades desterritorializadas - é isto a multiplicidade". Podemos considerar que o agenciamento de McQueen por meio do discurso da moda postula um sentido: Cuidado! Observem para onde estamos indo! Há beleza, mas também há morte... Assim, percebe-se um gradual, porém acelerado movimento na direção de uma cultura pós-humana. Entende-se que o mundo globalizado com o aporte das tecnologias de última geração apresenta-se como um imenso território rizomático, onde os mercados são tão múltiplos quanto as culturas. Se estamos aqui questionando as fronteiras do humano é porque, na verdade, estamos questionando as fronteiras do próprio corpo. Assim, a obra de McQueen questiona os limites do próprio corpo. Um sentido novo passa a desenhar o ser no horizonte do mundo pós-humano.

De acordo com a tese de Leroi-Gourhan, o processo de mutação das espécies se dá por uma série de liberações de tensões no corpo que permitem a evolução e a adaptação de determinados órgãos ao meio ambiente. 0 autor entende que "[...] em uma perspectiva que vai do peixe da era primária ao homem da era quaternária, acreditamos assistir a uma série de liberações sucessivas: aquela do corpo inteiro com relação ao 
elemento liquido, aquela da cabeça com relação ao solo, [...] finalmente, aquela do cérebro com relação à máscara facial" (LEROI-GOURHAN, 1964, p. 41).

Ainda segundo Leroi-Gourhan (1964, p. 41): "[...] fazendo a escolha de formas pertinentes colocamos em evidência uma longa pista regularmente ascendente sobre a qual cada liberação marca uma aceleração cada vez mais considerável". Vem ocorrendo um processo acelerado de "liberações", o que nos leva a questionar, assim como questiona McQueen com sua obra, sobre as possiveis transformações das formas do corpo, exigindo da imaginação do estilista estratégias de adaptação de seus artefatos, ou seja, novas linguagens para a moda, buscando contemplar as possíveis linhas de fuga das massas musculares emergentes.

\section{O híbrido e o louco}

A história da arte nos fornece ícones com formas hibridas e seres que nos fazem questionar os padrões e limites entre a loucura e a normalidade. "Bacon foi um desses acrobatas de labirintos. Buscava a excitação golpeando o medo, invadindo as sombras, dilacerando a carne, desfiando os nervos" (PARODE, 2012, p. 189). 0 híbrido e 0 louco aparecem como figuras míticas que assombram a ordem. Deleuze (1980, p. 198, tradução nossa) afirma que "[...] desfazer o organismo nunca foi se matar, mas abrir o corpo a conexões que supõem todo um agenciamento, de circuitos, de conjunções, de limiares, passagens e distribuições de intensidade, territórios e desterritorializações medidas à maneira de um topógrafo"3.

Assim, as figuras que remetem aos confrontos entre os padrões estabelecidos pela cultura e sociedade e às emergências de um corpo em devir, nos levam a questionar os valores subjacentes aos modelos idealizados e investidos de um poder de representação como ícones da beleza, da ordem e do bom. Do ponto de vista da representação visual, temos a oposição entre estéticas que exploram a dinâmica visual do movimento, como, por exemplo, as estéticas do Barroco, e aquelas que buscam a forma idealizada de um padrão estável, imóvel, transmitindo a sensação de eternidade, tal como ocorre nas estéticas do clássico.

Tanto McQueen quanto Bacon, ao expressarem em suas obras o movimento de um corpo, dado pela mutação e pelo rasgo de um limite sobre outro, liberam intensidades e agenciam uma produção de sentido que rompe com a arquitetura do poder da bela forma, instaurando pela dinâmica das sensações o princípio ativo da liberdade de expressão e da produção de diferenças. Como diz Deleuze (1981, p. 29), a propósito da lógica da sensação em Bacon, "[...] toda sensação, e toda Figura, já é da sensação 'acumulada', 'coagulada', como em uma figura de calcário"4.

Entretanto, apesar da diferença de formatos entre desfiles de moda e pinturas, consideramos que um desfile apresenta-se como um formato no qual podemos identificar pictogramas, massas plásticas que, para além da física, remetem a um imaginário que pode ser tanto mais associado ao movimento quanto ao seu contrário, ou seja, associado ao repouso.

No caso de McQueen, fica explícita sua preferência pelo movimento, pelo híbrido, pelo jogo entre o grotesco e o sublime da natureza à qual faz referência. 0 louco, no discurso de McQueen, aparece como a grande metáfora: a sua crítica da modernidade, do homem contemporâneo já enlouquecido pelo consumo e refém de um destino incerto. 0 louco é aquele homem que imagina o progresso sem considerar a sustentabilidade do planeta. Essa imagem crítica que nos aporta McQueen quanto ao homem moderno nos remete a uma imagem do proto-Renascimento produzida por Hieronymus Bosch, A nau dos loucos (La nefdes fous), que pode ser vista no Museu do Louvre, em Paris.

\section{A sustentabilidade e a crise}

Atlântida é um dos mitos mais instigantes trazidos por Platão em seus diálogos filosóficos. Ele descreve uma cidade extraordinária, abundante, com uma organização 
social e política avançada, e em relação harmoniosa com a natureza. Platão enfatiza o equilíbrio e as condições de sustentabilidade de Atlântida: "[...] a ilha produzia tudo em abundância, e, no que respeita aos animais, alimentava convenientemente os domesticados e os selvagens" (PLATÃO, 2012, p. 233). Este mito é uma das referências utilizadas por McQueen.

Em Plato's Atlantis, McQueen, numa perspectiva de crise ambiental, gera grande impacto na produção do seu último desfile. Ele deixou em evidência a problemática do desenvolvimento sustentável e uma possivel solução. Desafiando a natureza, inspirado nos processos evolutivos, ele propõe nas suas peças uma combinação de elementos que se relacionam intrinsecamente com os da teoria darwiniana ${ }^{5}$ : uma resposta aos problemas ecológicos contemporâneos?

A transmutação nos processos de adaptação das espécies ao entorno é próprio da natureza. Nesse sentido, a coleção de McQueen se encontra repleta de signos, que nos serviram de amostra para dar continuidade ao nosso ensaio.

Na segunda parte desse desfile, McQueen apresenta, com a simbologia expressa de suas peças, a perda de uma condição de homem que domina a natureza, ou seja, a grande exposição de componentes que afetam de modo extremo o planeta, misturado com o nascimento de um ser híbrido. Ele se serve do mito grego das Nereidas ${ }^{6}$, isto é, utiliza-se de figuras híbridas entre o humano e os peixes, lançando-se no paradigma evolutivo de adaptação das espécies.

No entanto, segundo Platão, a ilha pereceu sob a fúria do mar em menos de um dia, sem deixar vestígios. Em Plato's Atlantis, McQueen questiona a crise ambiental e gera grande impacto na produção do seu último desfile. Ele evidenciou a problemática do desenvolvimento sustentável. Desafiando os padrões da natureza e inspirado nos processos evolutivos, ele propõe uma combinação de elementos que se relacionam intrinsecamente com a teoria da transmutação darwiniana e consegue ilustrar de forma espetacular a emergência de corpos mutantes. Apresenta uma simbologia expressa nas peças: a possivel perda das condições de vida daquele que domina a natureza, ou seja, a grande exposição de componentes que estão supostamente afetando o equilibrio ambiental do planeta.

Assim, inspirado pelo mito de Atlântida ${ }^{7}$, o estilista parte para um jogo de descontrução das formas, ou seja, se valendo do mito, ele modifica as formas humanas, preparando suas modelos como ninfas do mar. Nas palavras de Svendsen (2010, p. 80-81), "[...] a moda é tambem, portanto, uma batalha constante para preencher 0 significado que está sendo gasto com crescente rapidez. Muitas vezes esses significados são preenchidos mediante refêrencias ao mundo além da moda".

Essa coleção de McQueen recupera a problemática ecológica, buscando adaptar seres míticos à realidade, fazendo uso de roupas extravagantes, penteados e maquiagem futuristas, buscando evidenciar a capacidade humana de se adaptar às condições do ambiente.

0 apelo à natureza está presente nos sapatos criados por McQueen, mimetizando peles de animais, vegetação e corais. Com essas criações o estilista explorou novas texturas e cores e inovou na forma do sapato feminino, respondendo à sua concepção de homem em processo de mutação. Fazem parte do chamado armadillo shoes ${ }^{8}$ uma ruptura com os padrões clássicos de sapatos, em que a forma seguiria as linhas do corpo. Nesse caso, a forma segue as linhas de um corpo mutante entre o mundo terrestre e o aquático ${ }^{9}$.

No caso da face das modelos, o que fica em evidência é a mutação extrema que os corpos estariam sofrendo, ou seja, a desconstrução da forma humana, embora com a mutação os rasgos de humanidade ainda estejam presentes nas modelos, é como se a adaptação ao mundo marinho estivesse em pleno processo. Pode-se considerar que a volta para a Atlântida de Platão se instaura no imaginário de McQueen e ele o realiza no plano tangível.

0 estilista experimenta o uso de novas texturas e formas. No caso das ninfas do mar, seus vestidos possuem uma forma assimétrica em perfeita sincronia com o corpo feminino, as cores em tons diversos com vários gradientes de azul, um possível recurso 
de camuflagem para ficarem indistintas no alto-mar. Além das formas volumosas expressarem o movimento d'água, os vestidos também apresentam uma gama de combinação das cores marinhas e de texturas com esquemas de peixes e corais. ${ }^{10}$

Após ter efetuado uma breve análise do desfile de McQueen, em especial a segunda parte, concluímos que a imagem de um ser híbrido é ponto focal da coleção. As combinações realizadas durante todo o desfile nos levam a pensar que o estilista estava considerando o surgimento de uma raça de super-homens capazes de se adaptarem à nova realidade. Esse indício faz surgir uma nova incógnita: será que, enquanto sociedade, daremos conta da problemática ecológica, ou será necessário o surgimento de um novo homem para dar continuidade ao que possa restar da humanidade?

\section{Considerações finais}

Este ensaio teve como proposta discutir e refletir sobre a matéria semiótica do estilista inglês Alexander McQueen, ou seja, buscamos os significantes de seu discurso, suas referências, e tentamos localizar as questões de fundo de sua obra. A sustentabilidade aparece como uma de suas inquietações, assim como o futuro da humanidade, levando-nos a questionar os limites da forma homem.

Com o aporte da filosofia da imanência, da estética e do design, construímos um referencial teórico para tratar as questões suscitadas pela moda de McQueen, identificando três eixos temáticos ao longo das nossas análises e reflexões: a imanência e 0 devir; o trágico e a deriva; o híbrido e o louco, sendo a sustentabilidade e a crise um tema transversal que aqui serviu como substrato para o nosso questionamento sobre a estética, a cultura e os devires do humano.

Identificando paralelos entre a estética de Francis Bacon e de Alexander McQueen, podemos explorar o universo de construção do sentido, buscando a lógica subjacente ao fluxo de desejo e aos agenciamentos de ambos os criadores. Por fim, a análise nos levou a identificar que a dinâmica de McQueen, na forma de espetáculo e estilo de moda, reservou não apenas uma crítica da modernidade tardia, mas também uma imagem do devir da humanidade. 
artigo ] FÁBIO PARODE | IONE BENTZ | MAXIMILIANO ZAPATA

\section{NOTAS}

${ }^{[1]}$ No original: Mais ce n'est pas en tant qu'il manque que le corps recherche ce qui lui est utile. C'est au contraire en tant qu'il affirme positivement sa propre nature ou sa propre vertu, donc en tant qu'il agit suivant ses propres lois, celles de sa nature communicationnelle.

[2] Veja: Bacon en 1952, retratado pelo fotógrafo John Deakin. Disponível em: <http://www.visualnews. com/2014/04/08/francis-bacon-man-behind-worlds-expensive-work-art/>, acesso em: 28 abr. 2015; e Alexander McQueen com máscara. Disponivel em: <http://www.google.com.br/imgres?imgurl=http:// www.tsquirrel.com/_data/photos/2015/03/6437_posts-tagged-alexander-mcqueen. jpg\&imgrefurl=http://www.tsquirrel.com/stv/alexandermcqueen $6437 \& h=225 \& w=225 \&$ tbnid $=$ 1xxriPnpAN9EoM:\&zoom=1\&tbnh=186\&tbnw=186\&usg=_8GDx1wkZwkQ_0N7JK_8DkGoNLyY= \&docid=youM1ABPH01aHM\&itg=1>. Acesso em: 28 abr. 2015.

${ }^{[3]}$ No original: Défaire l'organisme n'a jamais été se tuer, mais ouvrir le corps à des connexions qui supposent tout un agencement, des circuits, des conjunctions, des étagements et des seuils, des passages et des distributions d'intensité, des territoires et des déterritorializations mesurées à la manière d'un arpenteur.

${ }^{[4]}$ No original: Toute sensation, et toute Figure, est dejà de la sensation 'accumulée', 'coagulée', comme dans une figure de calcaire.

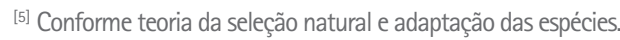

${ }^{[6]}$ Também conhecidas como ninfas do mar.

[7] Veja: Nereidas (Sea nymphs) no desfile Plato's Atlantis de McQueen. Disponivel em: <http://www.shhh.fm/ trilhas/19-atlantida/>. Acesso em : 28 abr. 2015.

${ }^{[8]}$ Armadillo shoes é um sapato lançado por Alexander McQueen em sua coleção primavera 2010.

[9] Veja:ModelosdeMcQueencommaquiagemeapliquesnorosto.Disponivelem:<http://www.behindthescenesmakeup. com/runway/alexander-mcqueen-at-paris-fashion-week/>. Acesso em: 28 abr 2015.

${ }^{[10]}$ Veja:Vestidos da coleção Plato's Atlantis. Disponivel em: <http://atramental.wordpress.com/2010/02/16/alexandermcqueen-passes/>. Acesso em: 28 abr. 2015

\section{REFERÊNCIAS}

ESPINOZA, B. Traité politique. Paris: Librairie générale française, 2002.

DELEUZE, Gilles. Francis Bacon: logique de la sensation. Paris: Éditions de la Différence, 1981. Tome 1.

0 que é a filosofia? Rio de Janeiro: Ed. 34, 1992.

1980.

; GUATTARI, Félix. Mille plateaux: capitalisme et schizophrenie 2. Paris: Les Éditions de Minuit,

Mil platôs: capitalismo e esquizofrenia. São Paulo, Ed. 34, 1995. v. 1.

LEROI-GOURHAN, André. Le geste et la parode: I. Technique et langage. Paris: Albin Michel, 1964.

PARODE, Fábio. Arte como dispositivo de poder. In: SILVA, Alexandre Rocha da; BENTZ, lone (Org.). Percursos semióticos: significação, codificação semiose e interface. São Paulo: Kazuá, 2012.

PLATÃO. Timeu-Crítias. Coimbra: Centro de Estudos Clássicos e Humanitários da Universidade de Coimbra, 2011. 